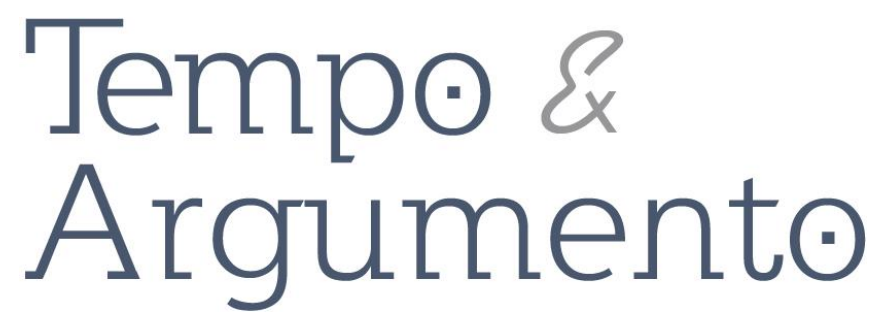

\title{
“Un pueblo, un líder, un Reich". El Nacionalsocialismo en el Caribe Colombiano: inmigrantes alemanes y Gleichschaltung (Coordinación) en Barranquilla durante la segunda mitad de la década de 1930
}

\begin{abstract}
Resumen
El presente artículo tiene como propósito analizar la manera como, hacia mediados de la década de 1930, surgió en la ciudad de Barranquilla, en el Caribe colombiano, una serie de grupos integrados por inmigrantes alemanes, que expresaron abiertamente su adhesión al Nacionalsocialismo. Se exploran de esos grupos sus formas de organización, sus manifestaciones políticas, los recursos de que hicieron uso para su labor propagandística, sus más que probables conexiones con el exterior $y$, en líneas generales, la manera como se constituyeron como manifestaciones locales de procesos globales caracterizados por la circulación de ideas y prácticas.
\end{abstract}

Palabras clave: Nazismo. Caribe Colombiano. Inmigrantes Alemanes.

\author{
Julián Andrés Lázaro Montes \\ Doctor en Historia por la Universidad Pablo \\ de Olavide, Sevilla. Docente Investigador \\ del Instituto Internacional de Estudios del \\ Caribe, Universidad de Cartagena. \\ Cartagena - COLOMBIA \\ julianandreslazaro@gmail.com \\ orcid.org/0000-0001-6559-8283
}

\section{Para citar este artículo:}

LÁZARO MONTES, Julián Andrés. “Un pueblo, un líder, un Reich”. El Nacionalsocialismo en el Caribe Colombiano: inmigrantes alemanes y Gleichschaltung (Coordinación) en Barranquilla durante la segunda mitad de la década de 1930. Tempo e Argumento, Florianópolis, v. 11, n. 28, p. 293 - 319, set./dez. 2019. 
"A people, a leader, a Reich". National Socialism in the

\section{Colombian Caribbean:}

German Immigrants and

Gleichschaltung

(Coordination) in

Barranquilla during the second half of the 1930 s

\begin{abstract}
The purpose of this paper is to analyze the way in the mid-1930s, a group of German immigrants who openly expressed their adherence to National Socialism emerged in the city of Barranquilla, in the Colombian Caribbean. These groups explore their forms of organization, their political manifestations, the resources they used for their propaganda work, their more than likely connections with the outside world, and, in general, the way they were constituted as local manifestations of global processes characterized by the circulation of ideas and practices.
\end{abstract}

Keywords: Nazism. Colombian Caribbean. German Inmigrants.
Um povo, um líder, um Reich". Nacional Socialismo no Caribe colombiano: imigrantes alemães e Gleichschaltung (Coordenação) em Barranquilla durante a segunda metade da década de 1930

\begin{abstract}
Resumo
O objetivo deste artigo é analisar como, em meados da década de 1930, uma série de grupos de imigrantes alemães que manifestaram abertamente sua adesão ao nacional-socialismo surgiu na cidade de Barranquilla, no Caribe colombiano. Esses grupos exploram suas formas de organização, suas manifestações políticas, os recursos que utilizaram para seu trabalho propagandístico, suas conexões mais do que prováveis com o mundo exterior e, em termos gerais, o modo como foram constituídas como manifestações locais de processos globais. caracterizado pela circulação de idéias e práticas.
\end{abstract}

Palavras-chave: Nazismo. Caribe Colombiano. Imigrantes Alemães.

\section{Introducción}

Los procesos políticos que se desarrollaron en la Europa de entreguerras no se limitaron en sus manifestaciones y efectos al territorio continental, puesto que encontraron formas de expresión y materialización en lugares distantes. La circulación de personas, mercancías, ideas, prácticas culturales y cualquier otro tipo de elemento asociado a la actividad humana en el marco de las lógicas de interconexión entre distintas zonas del mundo, determinó la aparición de fenómenos sociales que guardaban correspondencia o relación con otros parecidos o similares que sucedían en espacios distantes. 
En el contexto mencionado tenemos a Barranquilla, una población que hacia los años treinta se erigía como una de las urbes más dinámicas de Colombia. Ubicada a un costado del río Magdalena, principal arteria fluvial del país, y en cercanías al Caribe, conectada a través de líneas ferroviarias con los puertos cercanos en este mar, la particular posición de Barranquilla la convirtió en un escenario de comercio notable en el contexto nacional y con conexiones internacionales. Por Barranquilla salía una buena parte de los productos de exportación colombianos, al tiempo que artículos provenientes de Estados Unidos y Europa llegaban hasta ella para ser puestos en circulación, a través del río Magdalena, por una buena parte del territorio nacional (POSADA, 1998).

Desde finales del siglo XIX, en Barranquilla había venido haciendo presencia un número de inmigrantes alemanes no muy elevado, pero sí notablemente dinámico. De entre ellos, varios vieron en la creciente urbe caribeña la posibilidad de hacer negocios y prosperar, sobre todo conectando al puerto con los mercados internacionales, principalmente con algunas de sus ciudades de origen, entre ellas Hamburgo y Bremen, donde mantenían casas comerciales cuyas operaciones ampliaron a través de sucursales en Barranquilla.

La Primera Guerra Mundial significó una ruptura temporal de los flujos de productos en los circuitos comerciales instalados, sin embargo, una vez concluido el conflicto, algunos de los alemanes que se habían ido de Barranquilla retornaron, en tanto que otros, posiblemente motivados por sus conocidos o familiares, llegaron a la ciudad por primera vez. Esta situación se mantuvo en la década de 1930, momento en el cual la comunidad de alemanes en Barranquilla aparecía consolidada, siendo varios de sus integrantes prósperos empresarios de gran influencia en la ciudad (LÁZARO, 2012).

Las conexiones de estos empresarios y otros alemanes que llegaban a Barranquilla permitían el flujo comercial y de personas. Pero no era esto lo único que circulaba. En una época particularmente dinámica en política como la década de los treinta, cuando Alemania vivió el ascenso y la consolidación del Nacionalsocialismo, así como los primeros pasos hacia la guerra, los efectos de esos convulsionados años se sintieron en el Caribe. Así, Barranquilla fue escenario de las actividades de grupos y organizaciones de alemanes seguidores y, en algunos casos, vinculados con el Nacionalsocialismo, manifestaciones del 
lema “un pueblo, un líder, un Reich", que pretendía a través de una política de “coordinación” (Gleichschaltung) conectar a los alemanes en el exterior con los procesos que vivía la Alemania nazi.

El fenómeno de aparición de las mencionadas expresiones de adhesión al Nacionalsocialismo en el Caribe colombiano no ha sido trabajado en detalle, solo en algunos estudios generales sobre el tema del nazismo en Colombia o en otros enfocados en temáticas contemporáneas es mencionado de manera tangencial. A partir de lo anterior y ante la evidencia encontrada en archivos colombianos y extranjeros sobre organizaciones, individuos y actividades específicas relacionadas con el movimiento político alemán, se pueden plantear algunas preguntas que orienten un primer acercamiento al tema, entre ellas: ¿Qué actividades y qué formas de organización desplegó el Nacionalsocialismo en la comunidad de alemanes en Barranquilla durante los años treinta? ¿Cómo respondieron estos inmigrantes a la estrategia de "coordinación”, dinamizada desde el Reich y que fue adoptada por algunas organizaciones nazis que operaban en el Caribe colombiano? ¿Cómo reaccionó la sociedad local frente a las manifestaciones de adhesión al Nacionalsocialismo por parte de ciudadanos alemanes?

El presente trabajo está orientado a dar respuesta a estas preguntas y, en líneas generales, a trazar los contornos de lo que fue la llegada y recepción de ideas y prácticas nazis en un lugar distante del Reich, como lo era un puerto del Caribe colombiano, que, sin embargo, en el marco de la dinámica de circulación que caracterizaba al estado de integración de distintas zonas del planeta, recibió los efectos de uno de los procesos transformadores del siglo XX, el ascenso del nazismo al poder en Alemania y la segunda guerra mundial.

\section{Gleichschaltung o la estrategia de reorientación masiva sobre los alemanes}

La llegada del Nacionalsocialismo al poder en Alemania, en el año de 1933, representó el inicio de un proceso de reorientación de los diferentes aspectos de la vida del país, desde lo político hasta lo social, pasando por lo cultural y lo económico, influidos todos por una ideología que tenía como base a un nacionalismo para el cual los 
componentes fundamentales de una comunidad de personas, unidas incluso por encima de las fronteras políticas, eran lo cultural y lo racial. Precisamente, la concepción de que no importaba dónde se ubicara un alemán, este debía responder a un propósito específico que estaba asociado al fortalecimiento de su patria hizo que la “Gleichschaltung" (Coordinación), que fue la denominación que recibió la política de alineamiento de toda la vida alemana en torno al ideario nazi, trascendiera fronteras y llegara hasta lugares tan distantes como los países suramericanos, donde había presencia de inmigrantes alemanes a los que, a través de las organizaciones nazis o de los cuerpos diplomáticos y consulares, se transmitía un conjunto de contenidos y se propiciaban unas prácticas capaces de despertar, en no pocos de ellos, el entusiasmo por vincularse con el proyecto nacionalsocialista (GÖTZ, 2008).

Los primeros pasos en la implementación formal de la Gleichschaltung en Alemania, se dieron a lo largo del primer semestre de 1933, luego de la obtención de los plenos poderes para Hitler, a través de una serie de medidas político-administrativas (CARTER, 2014). Los nazis orientaron, entonces, su estrategia hacia el manejo de las distintas agremiaciones o formas de organización de los grupos sociales. Por ejemplo, en lo que respecta a los obreros alemanes, sector notablemente crítico frente al Nacionalsocialismo, el gobierno nazi ordenó, en mayo de ese mismo año de 1933, la prohibición de cualquier sindicato, creando como alternativa una organización que pudiera mantener bajo su control el Deutsche Arbeitsfront (DAF) o el Frente Alemán del Trabajo, en el cual quedaron incluidos, voluntaria o forzosamente, los trabajadores alemanes, incluyendo también a muchos que se encontraban fuera de su país. Un mes después le correspondió el turno a los partidos políticos. El 14 de julio de 1933 se estableció, por medio de un decreto, que en "Alemania existe como único partido político, el Partido Nacionalsocialista Alemán de los Trabajadores" (LOZANO, 2008, p. 67), con lo que, prácticamente, se cerraba cualquier vía para alternativas políticas distintas al Nacionalsocialismo.

Educación y cultura, también, quedaron controladas por los nazis muy pronto. Las escuelas alemanas debieron hacer considerables transformaciones en los contenidos que impartían, orientándolos hacia temas como la importancia de la pureza racial, la 
necesidad de preservar las tradiciones alemanas y la singularidad y la superioridad de los valores germanos. Las reformas también se extendieron a la educación superior, donde en procura de que fueran estrictamente aplicados y de que no existieran disidencias se crearon colectivos de estudiantes delatores (BROSZAT, 1981). En cuanto a la cultura, se estableció que las diferentes manifestaciones en este campo estarían orientadas a servir al Estado, y que las principales fuentes de inspiración de los artistas debían contener un fuerte componente ideológico nacionalsocialista, mirando a la mitología y a las tradiciones, entre otros temas, para cuyo cumplimiento se creó la Cámara de Cultura del Reich (MEJÍA, 1985; STEINWEIS, 1993).

Es importante señalar que, si bien es cierto la política de Gleichschaltung tuvo una elevada dosis de coerción, la persuasión jugó un papel relevante en el proceso de reorientación de los alemanes hacia el proyecto nacionalsocialista, en lo cual los medios de comunicación tuvieron un rol particularmente importante. Se recurría con frecuencia al uso de la imagen, antes que a los contenidos escritos, para poder llevar a un público más amplio las ideas basadas en simplificaciones reiteradas muchas veces, llevando a la práctica el consejo de Göebbels, un conocedor en la materia: "Machachar las mismas cosas a la gente hasta hacerlas de los nuestros" (DOMENACH, 1963, p.59).

Con la coerción y la persuasión operando de manera simultánea, el Nacionalsocialismo logró establecer un régimen de amplio control sobre la población alemana, que respondió en buena medida a los estímulos y que terminó por ofrecer un respaldo notable a muchas de las ideas y prácticas de los nazis. Esta situación no se dio únicamente en el Reich, los alemanes en el extranjero también fueron impactados por la estrategia de Gleichschaltung, adelantada por una serie de organismos cuya función era precisamente captar la atención de los alemanes en el extranjero para beneficio del régimen y de sus propósitos.

Para llevar el nazismo al exterior y articular a la población alemana en el extranjero con el proyecto nacionalsocialista, el régimen liderado por Hitler disponía del Ministerio de Asuntos Exteriores (Auswärtiges Amt, en adelante $A A$ ). Sin embargo, este organismo no fue de fácil control para los nazis, puesto que muchos de sus cargos más importantes estaban en manos de familias poderosas y tradicionales poco dadas a dejarse manejar por 
el nazismo (ALMEIDA, 2008). No obstante, el avance de los nazis no se detuvo y, para el año de 1937, de los 500 funcionarios de más alto nivel del AA, 200 se encontraban integrados al Partido Nacionalsocialista o a alguna de las organizaciones asociadas (FARÍAS, 2000). De igual forma, se logró que las delegaciones alemanas en el exterior contaran dentro de su cuerpo consular y diplomático con adeptos del nazismo, en muchas ocasiones en cargos importantes, lo que aseguraba que el gobierno nacionalsocialista podía contar, a través de estos agentes, con los recursos legales del Estado alemán para ser aplicados sobre los ciudadanos del Reich de acuerdo con su postura con respecto al régimen.

Funcionando como una parte activa del Ministerio de Asuntos Exteriores estaba la Organización del Partido Nacionalsocialista para el Extranjero (Auslandsorganisation der NSDAP, en adelante AO), que por estar estrechamente relacionada con el Partido resultaba notablemente dinámica y orientada de manera específica a la expansión de la ideología y prácticas nazis en las comunidades alemanas en el exterior. Surgida en el año de 1934 (MÜLLER, 1991), la AO era considera por Rudolf Hess como una de las divisiones administrativas del Reich, aunque con la singularidad de no estar contenida en un territorio específico, sino compuesta por tres grupos de ciudadanos alemanes: los que vivían fuera de Alemania, los marineros que se encontraban en alta mar y el personal administrativo que laboraba en las oficinas de la AO en suelo alemán (FARÍAS, 2000).

La función principal de la AO estaba orientada hacia la organización y el control de los diferentes colectivos nacionalsocialistas fuera de Alemania. Su crecimiento, tanto en recursos como en resultados, adquirió particular dinamismo luego de que fuera integrada en el Ministerio de Asuntos Exteriores, en el año de 1935, momento en el cual multiplicó su presencia y actividades en el exterior a través de organizaciones como el Frente Alemán del Trabajo, la Asociación de Mujeres Alemanas, las Juventudes Hitlerianas y las mismas células del partido nazi, todas las anteriores surgidas en una buena cantidad de países y organizadas en una estructura que se asimilaba a la del Partido Nazi y del gobierno del Reich en Alemania, basada en el Führerprinzip, es decir, en la obediencia a las orientaciones de un líder que no buscaba establecer consensos, sino dirigir al colectivo que le obedecía (BLUME, 2006). 


\section{Gleichschaltung y Nacionalsocialismo en el Caribe colombiano: el caso de los alemanes en Barranquilla y sus actividades políticas.}

Hacia el año de 1921, el empresario alemán Adolf Held, radicado en Barranquilla, le escribía una carta a su amigo colombiano Carlos Restrepo, en la que exponía sus percepciones acerca de la situación en que se encontraba su natal Alemania y del papel que cumplían, según él, los judíos en la escena política y económica internacional. Acerca de esto último señalaba que:

Francia está buscando por todos los medios posibles el dominio de las mejores hulleras alemanas [...] Es la tendencia del capital internacional de los judíos la de hacerse a todas estas riquezas y lo más grave es que la mayor parte de los hombres no quieren verlo. En la guerra pasada, todas las naciones han sufrido, las unas más y las otras menos; los únicos que han ganado son los judíos repartidos por el orbe y entrelazados entre sí íntimamente. No tienen vínculos con las naciones donde se hospedan y las naciones no son para ellos sino los medios de que valerse para obtener el dominio absoluto sobre todas las riquezas. (Citado en MEISEL, 1999, p.60)

Esta es una de las pocas expresiones que han sido encontradas de posición política crítica -y además antisemita-, del económicamente activo grupo de alemanes que vivían en la ciudad portuaria de Barranquilla en la década de los veinte. A falta de registros que evidencien lo contrario, esa década posterior a la Gran Guerra parece haber sido, antes que cualquier otra cosa, un momento durante el cual estos inmigrantes reactivaron las actividades comerciales que antes del conflicto los habían convertido en destacados empresarios en la ciudad y en la región.

La llegada del Nacionalsocialismo al poder y su iniciativa por agrupar en torno a sus ideas a la mayor cantidad de alemanes en el exterior a través de la política de Gleichschaltung, significó un cambio importante en cuanto a la posición y a las manifestaciones políticas de los alemanes en el Caribe colombiano. No hay referencia exacta de en qué momento las distintas organizaciones nazis iniciaron sus operaciones en la ciudad, sin embargo, se pueden encontrar registros fotográficos y otros documentos 
que indican que hacia mediados de la década del treinta el grupo nazi local ${ }^{1}$ y el Frente Alemán del Trabajo, por citar un par de casos, desarrollaban actividades en las que contaban con la participación de un buen número de inmigrantes alemanes residentes en Barranquilla².

De los distintos colectivos asociados o que habían adherido al Nacionalsocialismo, tal vez el de mayor actividad era el ya mencionado grupo nazi local, la pequeña rama del Partido que funcionaba en Barranquilla y que, al parecer, era el más activo en Colombia de los de su tipo, con múltiples acciones de difusión y consolidación del Nacionalsocialismo, entre ellas reuniones, actos conmemorativos ${ }^{3}$ y elaboración de contenidos impresos ${ }^{4}$, además de contar con varias figuras prominentes dentro de la estructura nacional, entre ellas el jefe de Grupo Nacional.

Como ya se hizo referencia en otro apartado de este trabajo, el Partido Nacionalsocialista Obrero Alemán fue una organización que se proyectó a nivel internacional con el propósito de vincular a los alemanes que se encontraban fuera de su país, y lo hizo a través de una vasta red de filiales que tenían presencia en 83 países, coordinadas desde Berlín por la Organización del Partido para el Exterior ( $A O)$, y siguiendo la estructura del Führerprinzip en la cual Wilhelm Von Bohle, jefe de la misma, ejercía como gran líder.

Colombia no estuvo al margen de esta iniciativa y en varias de sus ciudades como Bogotá, Medellín, Cali y Barranquilla se crearon pequeñas organizaciones articuladas con el partido nazi en Alemania, constituidas por inmigrantes alemanes que mostraron especial receptividad hacia, por lo menos, una buena parte de los postulados

\footnotetext{
${ }^{1}$ Departamento de Investigación e identificación de la Policía Nacional, Bogotá, 13 de enero de 1942. Archivo General de la Nación (AGN), Ministerio de Relaciones Exteriores (MRE), Diplomática y Consular, Caja 22, carpeta 176, folios 1-12.

2 En el Archivo General de la Nación, de la ciudad de Bogotá, reposa una documentación generada por las actividades de seguimiento desarrolladas por las autoridades colombianas y de otros países, básicamente Estados Unidos e Inglaterra, sobre las organizaciones nazis o las que estaban relacionadas con el Partido que hicieron presencia en Colombia. Dicha documentación aparece integrada en el Archivo del Ministerio de Relaciones Exteriores, Fondo Diplomática y Consular, Cajas 20 a 26, Carpetas 162 a 190.

3 Departamento de Investigación e identificación de la Policía Nacional, Bogotá, 13 de enero de enero de 1942. AGN, MRE, Diplomática y Consular, Caja 22, carpeta 176, folios 13-43.

4 Propaganda Actividades Nazis, 1937-1940. AGN, MRE, Diplomática y Consular, Caja 23, carpeta 184, folios 23-8-9-10.
} 
María Dietrich ha llamado una “tropicalización del nazismo” (DIETRICH, 2007).

Para el caso puntual de Barranquilla, en la costa Caribe colombiana, esta adaptación resultaba esencial, debido a las características socioeconómicas de la ciudad y de la región. A diferencia de lo que podía encontrarse en colonias alemanas de países como Chile o Brasil, donde estos inmigrantes erigían comunidades en alguna medida autárquicas, los alemanes en Barranquilla se dedicaban a actividades comerciales en las que tenían lugar relaciones con personas de distintas nacionalidades, credos y, por ponerlo en sus propios términos, razas. Incluso su consolidación como grupo de empresarios altamente dinámico había estado precedido, debía mucho y seguía condicionado por las relaciones con la sociedad local, con la que habían desarrollado un alto nivel de integración 5 . De esta forma, la segregación proclamada por el Nacionalsocialismo en sus postulados más radicales era para los alemanes en Barranquilla algo ilusorio e incluso altamente inconveniente (LAZARO, 2016).

No se conoce una fecha exacta que marque el inicio del grupo nazi en Barranquilla, pero sí se puede determinar a partir de los rastros de sus actividades que desde mediados de la década del treinta el colectivo aparece notablemente activo. Esta situación puede relacionarse con el hecho de que para esos años, específicamente en 1935, la Organización del Partido para el Exterior (Auslandsorganisation der NSDAP, AO) pasó a estar integrada en el Ministerio de Asuntos Exteriores (Auswärtigens Amt, AA), y con ello adquirió mayor capacidad de maniobra para respaldar las actividades de los distintos grupos nazis fuera del Reich. Así, existen registros fotográficos de la numerosa asistencia a las reuniones organizadas por el Nacionalsocialismo en Barranquilla, en las que tomaban

\footnotetext{
${ }^{5}$ Algunos registros notariales y otros documentos evidencian distintos casos de inserción de los alemanes en la sociedad local, así como formas de estrecha relación con locales: "Testamento abierto hecho por August Albert Johanes Lühr”, Barranquilla, 21 de agosto de 1920. Archivo Histórico del Atlántico (AHA), Fondo Notarías, Notaría Primera, Tomo 13, Escritura Pública Número 1822, folios 272-273; "Reconocimiento de varios hijos naturales que hace Franz Copell”, Barranquilla, 21 de junio de 1926. AHA, Fondo Notarías, Notaría Primera, Tomo 12, Escritura Pública Número 1147, folios 185-187; "Informe de la Sección de Extranjería e Identificación de la Policía Nacional”, Bogotá., 23 de mayo de 1943. AGN, MRE, Diplomática y Consular, Caja 23, Carpeta 181, folios 78-79.
} 
parte hombres, mujeres y niños, y en las que se portaban, por parte de no pocos de los asistentes, uniformes similares a los de las SA (Sturmabteilung), e incluso a los de las Juventudes Hitlerianas ${ }^{6}$.

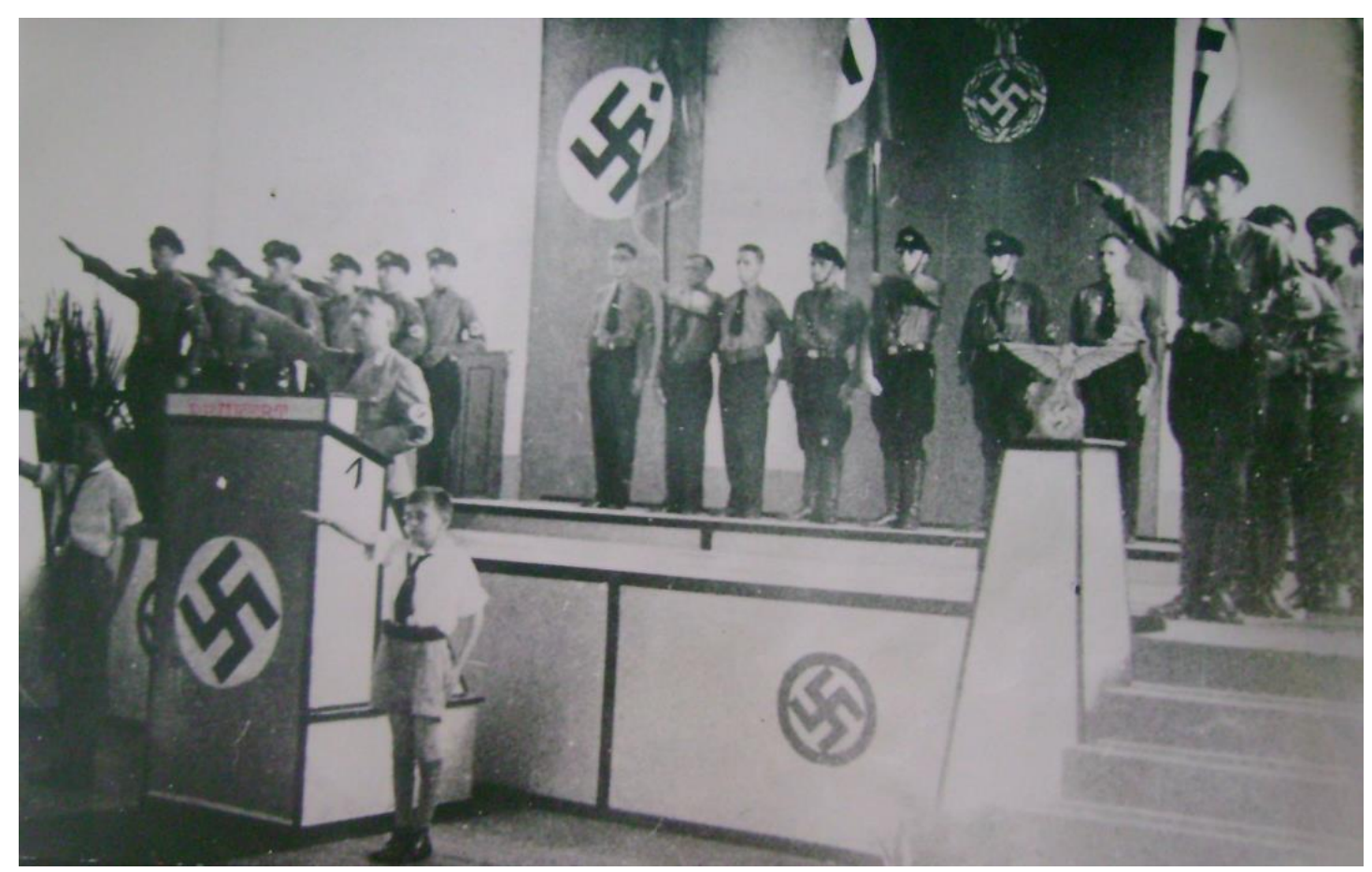

Imagen 1. Actividad del grupo nazi en Barranquilla, llevada a cabo en el gimnasio del Colegio Alemán en el año de 1936. (Fuente: Archivo General de la Nación, Fondo Archivo del Ministerio de Relaciones Exteriores, Diplomática y Consular, Caja 22, Carpeta 176, Actividades nazis 1942, folio 16).

El colectivo de alemanes en Barranquilla constituía un Stützpunkte, un Grupo de Apoyo $^{7}$, denominación que se daba a las organizaciones no tan numerosas y en ciudades no capitales y que se encontraba contenida en un Ortsgruppe, Grupo Local, que aglutinaba a los colectivos de una ciudad mayor o incluso de una región. Por encima del Grupo Local solo estaba el Landesgruppe, Grupo Nacional, que era la unidad contenedora de todos los colectivos de un mismo país. Por debajo del Grupo de Apoyo estaban, en orden descendente, los Blocks, Bloques, y las Zellen, Células, los primeros que hacían referencia a colectivos de pequeñas poblaciones y las segundas que era constituidas por grupos de vecinos (FARÍAS, 2000).

\footnotetext{
${ }^{6}$ Departamento de Investigación e identificación de la Policía Nacional, Bogotá, 13 de enero de enero de 1942. AGN, MRE, Diplomática y Consular, Caja 22, carpeta 176, folios 13-43.

7 Departamento de Investigación e identificación de la Policía Nacional, Bogotá, 13 de enero de enero de 1942. AGN, MRE, Diplomática y Consular, Caja 22, carpeta 176, folios 1-12.
} 
A la organización de actividades orientadas a la difusión del Nacionalsocialismo y al fortalecimiento del sentido de pertenencia a una comunidad por encima de las fronteras políticas, le acompañó la publicación y puesta en circulación de contenidos a través de medios impresos. Coincidiendo una vez más con el rol protagónico que adquirió la Organización del Partido para el Exterior a partir de 1935, es posible apreciar un particular dinamismo en lo concerniente a la utilización de recursos impresos para hacer llegar el mensaje nacionalsocialista a la comunidad alemana en Barranquilla.

Tal vez el caso más representativo de lo mencionado es el del magazín Karibischer Beobachter (Observador del Caribe), órgano del grupo nazi en el Caribe colombiano. Antes de 1937 lo que circulaba era una revista que contenía notas informativas sobre política internacional y alemana, y sobre asuntos de interés de la comunidad de alemanes en la ciudad, con una diagramación bastante básica y una calidad estética notablemente baja. La dinamización de la política de articulación de los alemanes en el exterior del Reich hizo que dicha revista, Ilamada "Boletín de Interés para la Comunidad de Alemanes en Barranquilla" 8 hasta antes del 1 de enero de 1937, cambiara su nombre por el de Karibischer Beobachter, y que, además, diera un salto de calidad notable en lo que respecta a la presentación, mostrando un diseño mucho más elaborado y con elementos característicos propios del Nacionalsocialismo, como los colores, negro y rojo, y algunos símbolos (LÁZARO, 2017). Adicional a lo anterior, un detalle de suma relevancia: los contenidos, presentados a través de artículos en alemán escritos muchos de ellos desde el Alemania, estaban sincronizados con la ideología nacionalsocialista, haciendo permanentes referencias a la superioridad (técnica, cultural, etc.) de los alemanes repotenciada por el Nacionalsocialismo 9.

Siguiendo la lógica del Führerprinzip, el colectivo nazi de Barranquilla tenía un líder, quien además era también el Landesgruppenleiter (Jefe de Grupo Nacional). Se llamaba Emil Prüfert (BIERMANN, 2001), y era un empleado de la Casa Helda, una firma comercial muy importante que se encargaba de la importación de artículos desde Europa y de la

8 Nachrichtenblatt der Deutschen Interessen Gemeinschaft, Barranquilla, 1934-1936. Instituto Iberoamericano de Berlín, Biblioteca, Magazin Friedrichshagen.

${ }_{9}$ Karibischer Beobachter, Barranquilla, 1937-1939. Instituto Iberoamericano de Berlín, Biblioteca, Magazin Friedrichshagen. 
Bohle, en Berlín. En Colombia estuvo ocupando el máximo cargo de la jerarquía nazi, hasta cuando fue obligado a abandonar el país durante la segunda guerra mundial. Hasta ese momento, Prüfert aparece sustituido, solo de manera temporal y por breves periodos de tiempo durante los cuales viajaba a Alemania, por Adolf Koch, otro empleado de la Casa Helda, Gerente de la sucursal de la vecina ciudad de Cartagena ${ }^{10}$.

La constante actividad del grupo nazi de Barranquilla generó algunas inquietudes en las autoridades locales, y muy pronto se iniciaron las labores de seguimiento por parte de la Policía Nacional. Los informes elaborados por agentes de esta institución, analizados a la luz de otras fuentes, aportan interesantes detalles acerca de la organización, conexiones y actividades nacionalsocialistas en el Caribe colombiano.

Junto a Emil Prüfert aparecen otros alemanes integrando el colectivo de nazis en Barranquilla, algunos de ellos particularmente dinámicos en las diferentes actividades que se llevaban a cabo. Uno de ellos era Friedrich Wilhelm Schmidt, quien, según informes policiales, había llegado de Hamburgo en el segundo semestre de 1938 para trabajar como representantes de la Fábrica de Jabones Hanseática. Schmidt era considerado por las autoridades colombianas como uno de los más entusiastas del Nacionalsocialismo y un constante animador de los encuentros del grupo local ${ }^{11}$.

Se sumaban a la lista de los considerados como nazis particularmente activos los alemanes Hermann Küehl, Hans Selbstaedt y George Roppel, todos ellos vinculados a la Sociedad Colombo-Alemana de Transportes Aéreos, una firma de aviación comercial constituida en 1919, pionera en el país y en Suramérica, y considerada como unas de las firmas más representativas de la presencia alemana en Colombia (LÁZARO, 2014). El

\footnotetext{
${ }^{10}$ Manjarrrés, M., "Informe de Manuel Manjarres, ex empleado del Consulado Alemán en Barranquilla, al Ministerio de Relaciones Exteriores", Barranquilla, 7 de octubre de 1940. AGN, MRE, Diplomática y Consular, Caja 21, Carpeta 171, folio 15.

11 Departamento de extranjería e identificación de la Policía Nacional, "Informe del Departamento de Extranjería e Identificación de la Policía Nacional”, Bogotá, 23 de mayo 1943. AGN, MRE, Diplomática y Consular, Caja 23, Carpeta 181, folio 70.
} 
primero de los mencionados, Küehl, se encontraba en Colombia desde principios de los años veinte, y en la Sociedad Colombo-Alemana de Transportes Aéreos (SCADTA) había ayudado a crear la "Sección Científica", departamento que contribuyó notablemente a la implementación de la aerofotografía en la definición de los límites de Colombia y en otras exploraciones desde el aire para empresas petroleras norteamericanas. Küehl fue también un alto asesor del gobierno de Colombia en asuntos aéreos durante el conflicto con Perú, en el año 1932, siendo condecorado con una alta distinción en 1933. Por su parte Selbstaedt, estaba en la plantilla de pilotos de SCADTA, en tanto que Roppel era contador de la misma empresa. ${ }^{12}$

Más allá de las posibles simpatías e incluso adhesiones reales de estos hombres, es preciso mencionar que la SCADTA estaba en el centro de las preocupaciones de los Estados Unidos. Para la segunda mitad de la década de 1930 y en la medida en que se aproximaba el inicio de la de los cuarenta, se evidenciaba con mayor claridad la actitud agresiva y expansionista de la Alemania nazi. En ese sentido, una firma con una notable participación alemana (una buena parte de los accionistas, pilotos, técnicos y personal administrativo era de origen alemán) ${ }^{13}$ y con simpatizantes y abiertos adeptos del Nacionalsocialismo operando en territorio suramericano, y más específicamente en zona relativamente cercana al Canal de Panamá, resultaba una presencia incomoda y de particular interés para el gobierno norteamericano y sus servicios de inteligencia, que presionaban al gobierno colombiano para que estuviera especialmente atento a las actividades de estos posibles agentes de la Alemania nazi (BUSHNELL, 1984).

Una característica que se puede encontrar en, por lo menos, una buena parte de las personas que integraban el grupo nazi local es el hecho de que, como en el caso de los ya mencionados, se encontraban relacionados con empresas destacadas que eran propiedad de alemanes o con una notable participación de capitales germanos. Algunos de ellos eran simplemente empleados, pero otros eran parte de la élite económica no

\footnotetext{
12 Departamento de extranjería e identificación de la Policía Nacional, "Informe del Departamento de Extranjería e Identificación de la Policía Nacional”, Bogotá, 23 de mayo 1943. AGN, MRE, Diplomática y Consular, Caja 23, Carpeta 181, folio 76.

13 Roca, Manuel. "Empleados alemanes de la SCADTA bajo contrato”, Bogotá, junio 23 de 1940. AGN, MRE, Diplomática y Consular, Caja 21, Carpeta 169, folios 31-37.
} 
solo de la comunidad alemana, sino también de la ciudad. En parte como consecuencia de lo anterior, era posible encontrarlos compartiendo espacios específicos y participando de diferentes iniciativas sociales o culturales. Por ejemplo, varios de ellos eran destacados miembros del Club Alemán (LAZARO, 2016), así como de la Sociedad Colegio Alemán, esta última a cargo de una institución educativa orientada a la formación de los hijos de alemanes y también de jóvenes de familias destacadas no alemanas (LOBO Y LOBER-SIES, 1994).

Especial atención ponían los servicios de inteligencia colombianos y de Estados Unidos e Inglaterra, que ya venían operando a finales de los años treinta, en el grupo de colegios alemanes que funcionaban en el país, a los que se llegó a considerar como centros de difusión de la cultura nacionalsocialista, sobre todo debido a las presuntas tareas que cumplían los profesores llegados a estas instituciones después del arribo de Hitler al poder. Uno de esos docentes considerados como posibles difusores de las ideas nazis en Barranquilla era Walter Plass, un "fanático", según informes de las autoridades colombianas, que arribó a la ciudad en el año de 1936, considerado por los servicios de inteligencia de Colombia como un partidario entusiasta del Nacionalsocialismo que asistía frecuentemente a las reuniones del grupo local que se desarrollaban en el Consulado alemán ${ }^{14}$. Plass llegó al cargo de Director del Colegio Alemán en el periodo comprendido entre 1940 y 1942, momento en el cual y como consecuencia de la guerra mundial, se incrementaron las labores de seguimiento sobre los alemanes por parte de los servicios de seguridad nacionales y extranjeros, todo lo cual resultó, finalmente, en el cierre de la institución educativa en febrero de 1942, a lo que le siguió el retorno a su país del entonces director Plass y de los profesores alemanes del colegio (LOBO y LOBER-SIES, 1994).

Además de las labores de difusión y consolidación de las ideas nacionalsocialistas, los integrantes del grupo nazi de Barranquilla, sobre todo aquellos que tenían responsabilidades diplomáticas o consulares con el Reich, desarrollaban actividades de recolección de información sobre temas tan diversos como la situación económica y

\footnotetext{
${ }^{14}$ Manjarrrés, M. "Informe de Manuel Manjarres, ex empleado del Consulado Alemán en Barranquilla, al Ministerio de Relaciones Exteriores", Barranquilla, 7 de octubre de 1940. AGN, MRE, Diplomática y Consular, Caja 21, Carpeta 171, folio 15.
} 

capacidad de influencia que tenían sobre la sociedad local. Un ejemplo de ello se puede encontrar en la situación que vivió en el año de 1939 el austriaco (para ese momento ciudadano del Reich) Peter Paul Von Bauer, quien, en su condición de accionista mayoritario y representante de la Sociedad Colombo-Alemana de Transportes Aéreos ${ }^{15}$, tuvo que presentarse ante el Cónsul alemán en Barranquilla para informar de manera detallada acerca de la firma de aviación comercial. Esta y otras informaciones recogidas por las autoridades consulares y otras organizaciones nazis eran enviadas al Ministerio de Relaciones Exteriores del Reich. ${ }^{16}$

Además de ser un centro de recopilación de información para el posterior envío a Alemania, el Consulado servía también para las reuniones de los adeptos del Nacionalsocialismo en Barranquilla. En sus instalaciones se congregaban los integrantes del grupo local para recibir instrucciones, formular estrategias y planificar actividades orientadas a la difusión del ideario nazi en la comunidad de alemanes en la ciudad y en otras ciudades cercanas. También se encontraban para ponerse al tanto y discutir sobre los principales acontecimientos que se estaban desarrollando en Europa, especialmente sobre aquellos en los que el Reich cumplía un papel protagónico, como la anexión de Austria o el desmembramiento de Checoslovaquia.

Precisamente, la agresiva campaña de expansión de Hitler en Europa de los últimos años de la década del treinta dio lugar a que de este lado del Atlántico sus seguidores fueran observados con mayor recelo por parte de las autoridades policiales. El Caribe colombiano no escapó a esta situación, y probablemente a causa de ello los miembros del grupo nazi local optaron por trasladar en 1939 sus actividades a la cercana

\footnotetext{
${ }^{15}$ La situación de Von Bauer era realmente diferente. Había sido el principal accionista de la compañía aérea SCADTA hasta comienzos de los años treinta, cuando sus acciones fueron vendidas, en secreto, a la Pan American Airways, sin embargo, la transacción no se hizo pública sino hasta el final de la década, por lo que, hasta entonces, Von Bauer siguió fungiendo como accionista mayoritario y hombre fuerte de la empresa.

16 Manjarrrés, M. "Informe de Manuel Manjarres, ex empleado del Consulado Alemán en Barranquilla, al Ministerio de Relaciones Exteriores", Barranquilla, 7 de octubre de 1940. AGN, MRE, Diplomática y Consular, Caja 21, Carpeta 171, folio 15-17.
} 
Pero el distanciamiento del núcleo urbano de Barranquilla no significó una disminución de los niveles de observación a que eran sometidas las actividades del grupo de alemanes nazis. Informes del Ministerio de Relaciones Exteriores de Colombia hacen referencia a que en la nueva sede de reunión del partido -e incluso en la antigua del Consulado- se seguían llevando a cabo reuniones en las que, entre otras cosas, se apreciaban documentales relacionados con el Nacionalsocialismo, se preparaban actividades y se planeaba la distribución de propaganda que llegaba de Alemania, la cual era puesta en circulación no solo en Barranquilla, sino también otras poblaciones colombianas donde existían organizaciones o simples simpatizantes nazis ${ }^{18}$.

La propaganda impresa, que circulaba también en español ${ }^{19}$, constituía una poderosa herramienta de difusión del ideario nazi, pero por sí sola no bastaba para mantener el entusiasmo entre los seguidores del Nacionalsocialismo en Barranquilla. Su adhesión debía ser reforzada con actos grupales que alimentaban el sentimiento de unidad que se buscaba estimular desde Alemania. La Gleichschaltung solo era posible a través de una inmersión plena en la mística nazi que se conseguía en las celebraciones y los actos ceremoniales a través de una atmósfera construida para tal propósito.

Las imágenes que se pueden apreciar de los eventos del grupo nazi de Barranquilla evidencian el interés por crear los escenarios para su desarrollo, donde se replicaban, en la medida de lo posible, las puestas en escena del nazismo en Alemania. Los símbolos más característicos del Nacionalsocialismo estaban siempre presentes y se imponían en los escenarios. Uno de esos símbolos era el águila, considerada por los ideólogos del

\footnotetext{
${ }^{17}$ Manjarrrés, M. "Informe de Manuel Manjarres, ex empleado del Consulado Alemán en Barranquilla, al Ministerio de Relaciones Exteriores", Barranquilla, 7 de octubre de 1940. AGN, MRE, Diplomática y Consular, Caja 21, Carpeta 171, folio 16.

${ }^{18}$ Manjarrrés, M. "Informe de Manuel Manjarres, ex empleado del Consulado Alemán en Barranquilla, al Ministerio de Relaciones Exteriores", Barranquilla, 7 de octubre de 1940. AGN, MRE, Diplomática y Consular, Caja 21, Carpeta 171, folios 16-17.

19 Un ejemplo de esta propaganda se puede encontrar en los discursos de Hitler, traducidos al español y posteriormente difundidos en Colombia: "Discurso del Führer y canciller Adolf Hitler ante el Reichstag el 30 de enero de 1937”. S.L, S.F. AGN, MRE, Diplomática y Consular, Caja 23, Carpeta 184, folio 8.
} 
Nacionalsocialismo como el animal que, por estar en las alturas y encima del resto de seres vivientes, se asimilaba a la tan mencionada raza aria (MEJÍA, 1985). La esvástica era un símbolo que, como era de esperarse, no podía faltar y adornaba abundantemente los escenarios de las distintas actividades del grupo nazi en Barranquilla, acompañado en múltiples ocasiones por las imágenes de Hitler y de otros dirigentes Nacionalsocialistas.

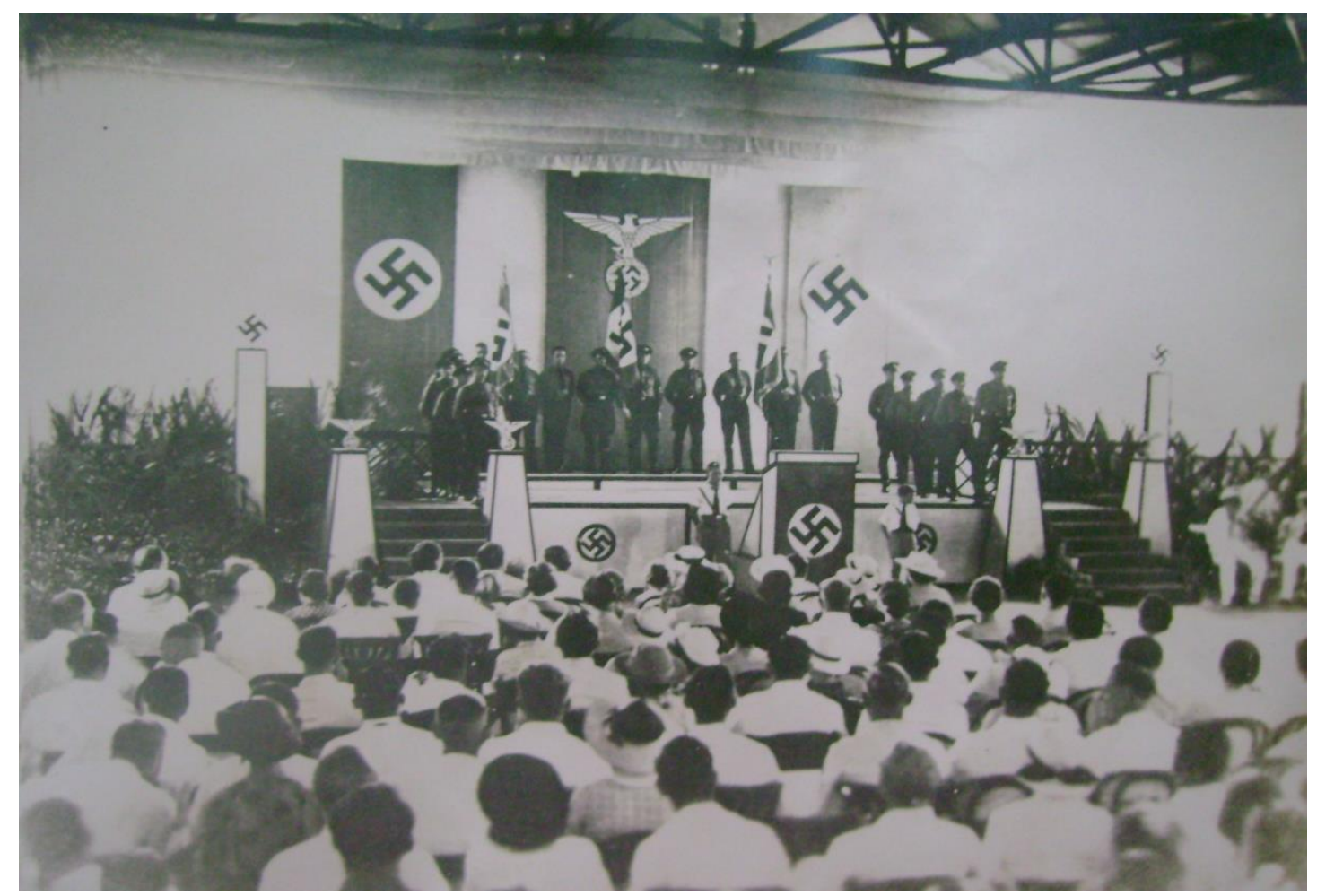

Imagen 2. Actividad del grupo nazi en Barranquilla, llevada a cabo en el gimnasio del Colegio Alemán, en el año de 1936. (Fuente: Archivo General de la Nación, Fondo Archivo del Ministerio de Relaciones Exteriores, Diplomática y Consular, Caja 22, Carpeta 176, Actividades nazis 1942, folio 16).

Los grandes eventos del Nacionalsocialismo en Barraquilla se efectuaban para conmemorar fechas importantes del calendario nazi, que estaba integrado tanto por celebraciones propias de Alemania como por festividades internacionales. Así, entre los principales eventos a los que acudía de manera masiva la comunidad alemana en la ciudad estaba la celebración del $1^{\circ}$ de mayo, aunque con una orientación nacionalsocialista que resaltaba, entre otras cosas, el papel de los trabajadores en la construcción de la nueva Alemania ${ }^{20}$. También se conmemoraba el aniversario de la llegada del Nacionalsocialismo

\footnotetext{
${ }^{20}$ Departamento de Investigación e identificación de la Policía Nacional, Bogotá., 13 de enero de enero de 1942. AGN, MRE, Diplomática y Consular, Caja 22, carpeta 176, folios 13-15.
} 
al poder, el cumpleaños de Hitler y el día del Partido Nacionalsocialista, entre otras fechas clave consagradas en el calendario nazi ${ }^{21}$.

Las imágenes que registran las actividades de proselitismo del grupo nazi en Barranquilla dan cuenta de asistencias masivas, lo que a simple vista podría significar que el colectivo nazi en sí era numeroso. Sin embargo, la asistencia a los eventos no era sinónimo de pertenencia al colectivo nazi en sí, puesto que la condición de asociado al mismo se alcanzaba previo cumplimiento de algunos requisitos que evidenciaran un compromiso pleno con el Nacionalsocialismo. De hecho, las listas que elaboró la policía colombiana contenían referencias acerca de las personas que tenían algún nivel de relación con las actividades nazis, estableciendo una especie de categorización diferenciadora en una escala que se movía entre quienes mostraban un alto nivel de adhesión al Nacionalsocialismo y quienes no eran nazis, pasando por algunos a los que se consideraba como sospechosos de serlo. ${ }^{22}$

Está documentado para otros países de América Latina la forma como se limitaba el ingreso al núcleo de los grupos nazis que operaban en ellos, lo que, teniendo en cuenta que se seguía un modelo formulado desde el Reich, da lugar a hacer extrapolaciones con el caso de Barranquilla. Así, es altamente probable que algunos de aquellos alemanes que Ilevaban en Barranquilla residiendo desde principios de los años veinte o antes, fueran observados con desconfianza por no estar estrechamente relacionados con las penurias económicas que vivió Alemania a lo largo de esa misma década y con el proceso de ascenso del Nacionalsocialismo y Gleichschaltung; y más recelo aún despertaban si evidenciaban particular integración en la sociedad local. Ello no significaba que perdieran sus derechos como alemanes o que no fueran importantes para la política exterior del Reich, pero su ingreso en el círculo de integrantes del grupo nazi local era menos sencillo de lo que había sido para quienes se encontraban, por lo menos en apariencia, más imbuidos ideológicamente de Nacionalsocialismo (DIETRICH, 2007).

\footnotetext{
${ }^{21}$ Departamento de Investigación e identificación de la Policía Nacional, Bogotá, 13 de enero de enero de 1942. AGN, MRE, Diplomática y Consular, Caja 22, carpeta 176, folios 16-27.

22 "Informe de Alemanes en Barranquilla", Barranquilla, s.d. AGN, MRE, Diplomática y Consular, Caja 22, Carpeta 176, folios 25-32.
} 
Así como las diferentes actividades de los adeptos del Nacionalsocialismo en Barranquilla no pasaron desapercibidas para las autoridades locales y para los servicios de inteligencia nacionales y extranjeros, la sociedad local tampoco fue ajena a estas manifestaciones políticas, e incluso culturales, con las que no se encontraba relacionada directamente y que, por esa misma razón, debieron de parecerles extrañas. Sin embargo, el alto nivel de aceptación que tenían los alemanes en la ciudad, debido a la, ya para ese momento, larga trayectoria de algunas empresas y empresarios germanos en Barranquilla, dinamizadores de los procesos de desarrollo económico de la urbe caribeña, dio lugar a una reacción que osciló, por lo menos hasta antes del inicio de la segunda guerra mundial, entre la indiferencia y la simpatía. Los alemanes estaban integrados hasta un nivel importante en la sociedad local, sobre todo entre la élite; y a nivel nacional muchos de ellos eran personas distinguidas, debido a la trascendencia de varias de sus empresas.

Sin embargo, no todos en Barranquilla reaccionaron de la misma manera frente a las actividades desplegadas por el colectivo nazi local y sus simpatizantes. Algunos extranjeros que habían llegado a la ciudad en tiempo reciente y que debieron salir de su país de origen en gran medida a causa de la política expansionista del Tercer Reich en Europa, lideraron manifestaciones en contra de cualquier forma de expresión de los fascismos en territorio americano.

Uno de esos extranjeros que se pronunció en contra de las actividades nazis en el Caribe colombiano fue el judío rumano Isaac Croitoru Rotbaum, de profesión abogado y quien había tomado parte en la fundación del Partido Radical Campesino en su país de origen, de donde debió salir huyendo debido a las persecuciones del movimiento político antisemita y de derechas conocido como la Guardia de Hierro. Nada más llegar a Barranquilla en el año de 1937, Croitoru Rotbaum combinó sus actividades comerciales, de las cuales obtenía los medios para subsistir, con la denuncia abierta de las organizaciones nazis que operaban en la ciudad. Dichas denuncias circularon con mayor fuerza a través de un semanario que el mismo rumano creó, Ilamado “La Victoria”, en el que publicaba textos escritos por otros judíos que se encontraban en Barranquilla y también algunos trabajos que llegaban desde el exterior (MANCO y WATNIK, 2001). 
Hubo otros casos de extranjeros que, si bien no se manifestaron fuertemente ante las expresiones del Nacionalsocialismo en Barranquilla, sí adoptaron unas posturas en su vida cotidiana que evidenciaban un rechazo a la política exterior de Alemania. Uno de ellos fue el judío austriaco Wilhelm Retnizcher, también abogado, que debió salir de su país luego de que este fuera anexionado al Reich, y quien en su día a día en Barranquilla evitaba el contacto con ciudadanos alemanes e italianos. ${ }^{23}$

\section{Conclusión}

Para los años treinta del siglo XX las formas de conexión entre diferentes lugares del mundo a partir del desarrollo de las comunicaciones habían dado lugar a una dinámica de circulación de personas, bienes, ideas, prácticas y otras expresiones de la actividad humana. Colombia no estaba al margen de esta situación, y en ese sentido el Caribe colombiano actuaba como puente entre el país y los fenómenos internacionales, con especial protagonismo entre finales del siglo XIX y las primeras décadas del XX de la ciudad de Barranquilla, puerto especialmente dinámico y conectado con sus pares del Caribe, Norteamérica y Europa.

A partir de las características de circulación que han sido mencionadas y de la presencia en la ciudad de un grupo de inmigrantes alemanes, empezaron a aparecer a mediados de los años treinta en Barranquilla una serie de expresiones materializadas en colectivos, actividades y otras manifestaciones de adhesión, apoyo y, en ocasiones, articulación con el proyecto nacionalsocialista alemán.

La aparición de este tipo de fenómenos y el abordaje que sobre el mismo se ha hecho a lo largo de las páginas anteriores, deja a las claras varios aspectos que es preciso señalar como conclusiones de este trabajo.

En primer lugar, queda en evidencia que América y los inmigrantes alemanes en el continente no estaban al margen del interés del régimen de Hitler y de su proyecto político-ideológico. Aún aquellos alemanes que residían en un país de relativamente poca

\footnotetext{
23 "De la Sección de Extranjería e Identificación de la Policía Nacional al Director General” (Barranquilla, 23 de mayo de 1943), AGN, MRE, Diplomática y Consular, Caja 23, Carpeta 181, folio 82.
} 
influencia económica y política en la escena internacional como Colombia, tenían su lugar en la estrategia de preguerra del Reich. La puesta en ejecución de dicha estrategia, que tenía entre sus componentes la integración en el proyecto nazi de los alemanes en el exterior, no era excluyente ni quedaba limitada en su accionar a grandes centros de poder económico o político, sino que, por el contrario, apuntaba a establecer conexiones con las diferentes comunidades de alemanes allí donde estuvieran residiendo. Es el caso que se estudia en este trabajo, pero también es un fenómeno que se pone en evidencia a través de, por ejemplo, la proyección de la influencia del Nacionalsocialismo en zonas rurales y pequeñas poblaciones con presencia germana en países como Brasil o Chile.

Por otro lado, es importante llamar la atención sobre un aspecto de este fenómeno del surgimiento de expresiones de adhesión y/o apoyo al Nacionalsocialismo en el Caribe colombiano, y es el hecho de que el contexto en el que se desarrollaba la vida de estos inmigrantes representó en buena medida un obstáculo para su plena articulación con el proyecto nazi. No obstante, los alemanes en la ciudad en esa segunda parte de los años treinta lograron desarrollar formas de negociación, arreglos entre el requerimiento que les llegaba de Alemania (al que no pocos de ellos respondían con entusiasmo) y el cumplimiento de las necesidades de adaptación al medio local. Así las cosas, siguieron un camino intermedio entre los mensajes cada vez más radicales enviados por las autoridades nazis desde Alemania y el comportamiento prudente que debían mantener en un medio ajeno. Desarrollaron, entonces, un nazismo con muchos matices, más nominal que real, más de rituales privados (aunque no absolutamente ocultos) que de prácticas públicas, más de discursos escritos (a través de propaganda) que de acciones puntuales con relación a otros grupos humanos, todo ello en procura de mantener estable su posición con los poderes y la opinión pública local.

Adicional a lo anterior y en lo que respecta puntualmente a la historia de Colombia, el caso analizado pone en evidencia la necesidad de unas miradas mucho más ambiciosas y abarcadoras en la historiografía nacional, que entren a considerar fenómenos regionales como parte de los análisis integrales que requiere la construcción de una historia verdaderamente nacional. En correspondencia con lo anterior, Barranquilla en particular puede considerarse para esos primeros años del siglo XX como un escenario de 
especial interés para identificar formas de impacto y efectos de la situación internacional en el país. Su condición de urbe en crecimiento, en buena medida a partir de la dinámica del comercio de importación y exportación, y su funcionalidad como punto de conexión entre el territorio colombiano y el resto del mundo, la convirtieron en un espacio sensible a los fenómenos mundiales cuyos efectos se sentían posteriormente en otros lugares del territorio nacional.

También en relación con lo anterior, estos espacios periféricos como Barranquilla, que debían buena parte de su dinámica a la conexión con los procesos internacionales, constituyen escenarios a escala ideales para el análisis de fenómeno mundiales: en primer lugar, para determinar y comprender los efectos de esos grandes fenómenos y sus manifestaciones en puntos distantes de los grandes escenarios; y en segundo lugar, para considerar las especificidades, las singularidades que se daban en espacios menores y periféricos, es decir, la forma como los actores sociales, aún sin deslindarse totalmente de la dinámica de los grandes fenómenos mundiales, e incluso actuando en correspondencia con ellos, configuraban sus propias lógicas adaptadas al medio local en que se encontraban.

A partir de lo expuesto en este trabajo, quedan claros algunos rasgos del fenómeno de surgimiento y desarrollo de expresiones de apoyo al Nacionalsocialismo en el Caribe colombiano. No obstante, otros tantos interrogantes se abren para el investigador interesado. Por ejemplo, bien vale preguntarse hasta qué punto la totalidad de la comunidad alemana en Barranquilla respondió con entusiasmo y de manera autónoma al llamado de su gobierno a articularse con el proyecto nazi. Pregunta de difícil respuesta, puesto que, por una parte, estaba el hecho puntual de la existencia de una visión positiva sobre el nazismo basada en buena medida en comunicaciones y propaganda, pero por otra estaban los recursos de presión que, desde los organismos diplomáticos y consulares y de las mismas organizaciones nazis o asociadas funcionando en la ciudad, se podía ejercer sobre los ciudadanos del Reich. Tal vez la respuesta al interrogante inicial esté en un punto intermedio que conjugue las dos circunstancias descritas. Adicional a la inquietud anterior, salta la pregunta acerca de la eficacia en el cumplimiento de las tareas asignadas a las organizaciones nazis o relacionadas con el 
Reich en Barranquilla, atendiendo a aspectos como proyección de actividades a desarrollar, recursos disponibles y objetivos puntuales alcanzados. De algunos individuos y grupos se decía, por ejemplo, que tenían la finalidad de servir como cuerpos de inteligencia que captaban información para Berlín. Solo una búsqueda en profundidad en archivos alemanes puede aportar referencias más claras acerca de la importancia de estos grupos para los organismos nazis en Alemania y el aporte que pudieron llegar a hacer a los objetivos en el exterior del Tercer Reich.

\section{Referencias}

ALMEIDA, Fabrice. Hight society in the Third Reich. Paris: Polity Press, 2008.

BIERMANN, Enrique. Distantes y distintos: los emigrantes alemanes en Colombia, 19391945. Bogotá: Universidad Nacional de Colombia, 2001.

BLUME, Marco. Gleichshaltung und Führerprinzip- zur rolle des DFB in der Zeit des nationalsozialismus in der Zeit von 1933-1945. Münich: GRIN Verlag, 2006.

BROSZAT, Martin. The Hitler State: the foundation and development of the internal structure of the Third Reich. Londres: Longman Group, 1981.

BUSHNELL, David. Eduardo Santos y la política del Buen Vecino, 1938-1942. Bogotá: El Áncora, 1984.

CARTER, Benjamin. Burning the Reichstag: an investigation into the Third Reich's enduring mistery. New York: Oxford University Press, 2014.

DEPARTAMENTO DE EXTRANJERÍA E IDENTIFICACIÓN DE LA POLICÍA NACIONAL. Informe del Departamento de Extranjería e Identificación de la Policía Nacional. Bogotá, 23 mayo 1943. Archivo General de la Nación, Ministerio de Relaciones Exteriores, Diplomática y Consular, Caja 23, Carpeta 181.

DEPARTAMENTO DE INVESTIGACIÓN E IDENTIFICACIÓN DE LA POLICÍA NACIONAL. Bogotá, 13 enero 1942, AGN, MRE, Diplomática y Consular, Caja 22, Carpeta 176.

DE LA SECCIÓN de Extranjería e Identificación de la Policía Nacional al Director General. Barranquilla, 23 mayo 1943. Archivo General de la Nación, Ministerio de Relaciones Exteriores, Diplomática y Consular, Caja 23, Carpeta 181. 
DIETRICH, Ana María. Nazismo Tropical?: o partido nazista no Brasil. São Paulo: Tesis de Doctorado, Universidad de Sao Paulo, 2007.

DISCURSO del Führer y canciller Adolf Hitler ante el Reichstag el 30 de enero de 1937. [S.I.], AGN, MRE, Diplomática y Consular, Caja 23, carpeta 184.

DOMENACH, Jean Marie. La propaganda política. Bogotá: El Faro, 1963.

FARÍAS, Víctor. Los nazis en Chile. Barcelona: Editorial Seix Barral, 2000.

GÖTZ, Aly. La utopía nazi: cómo Hitler compró a los alemanes. Barcelona: Crítica, 2008.

INFORME de alemanes en Barranquilla. Barranquilla, Archivo General de la Nación, Ministerio de Relaciones Exteriores, Diplomática y Consular, Caja 22, Carpeta 176.

INFORME de la Sección de Extranjería e Identificación de la Policía Nacional. [S.I.], 23 mayo 1943, AGN, MRE, Diplomática y Consular, Caja 23, Carpeta 181.

KARIBISCHER Beobachter. Barranquilla, 1937-1939, Instituto Iberoamericano de Berlín, Biblioteca, Magazin Friedrichshagen.

LÁZARO, Julián Andrés. Los medios impresos como recurso para la difusión del Nacionalsocialismo: sobre boletines y magazines nazis circulando en el Caribe colombiano, 1935-1939. Memorias: Revista Digital de Arqueología e Historia desde el Caribe, Barranquilla, Año 13, n. 33, sept./dic. 2017, p. 66-91.

LÁZARO, Julián Andrés. SCADTA: el viejo anhelo de conquistar el cielo. En: FERRO BAYONA, Jesús, IBARRA, Octavio y GÓMEZ, Eduardo (Ed.). Historia Empresarial de Barranquilla (1880-1980). Barranquilla: Ediciones Uninorte, 2014, 183-224.

LÁZARO, Julián Andrés. Presencia extranjera en Barranquilla: el caso de los alemanes, sus actividades económicas y el fin de su influencia en la urbe caribeña, 1930-1941. Memorias: Revista Digital de Arqueología e Historia desde el Caribe, Barranquilla, Año 9, N. 16, Mayo 2012, p. 165-196.

LOBO, Severino; LOBER-SIES, Dieter. Historia del Colegio Alemán, 1912/13-1994. Traducción al español: Dörthe de Uribe. Barranquilla: Editorial Mejoras, 1994.

LOZANO, Álvaro. La Alemania nazi. Madrid: Marcial Pons Historia, 2008.

MANCO, Dino; WATNIK, José. Vidas destacadas. Barranquilla: Ed. Mancomunicaciones, 2001. 
MANJARRES, Manuel. Informe de Manuel Manjarres, ex empleado del Consulado Alemán en Barranquilla, al Ministerio de Relaciones Exteriores. Barranquilla, 7 oct. 1940. Archivo General de la Nación (AGN), Ministerio de Relaciones Exteriores (MRE), Diplomática y Consular, Caja 21, Carpeta 171.

MEISEL, Adolfo. Los alemanes en el Caribe colombiano: el caso de Adolf Held, 1880-1927. Boletín Cultural y Bibliográfico del Banco de la República, Bogotá, v. 35, n. 49, 1999.

MEJÍA, María Victoria. 1985. La propaganda totalitaria del Tercer Reich. Medellín: Editorial Universidad de Antioquia.

MÜLLER, Jurgen. Nationalsozialismus in Lateinamerika. Die auslansorganization der NSDAP in Argentinien, Brasilien, Chile und Mexico, 1931-1945. Stuttgart, Historische Zeitschrift 1, n. 269, p. 241-243.

NACHRICHTENBLATT der Deutschen Interessen Gemeinschaft. Barranquilla, 1934-1936, Instituto Iberoamericano de Berlín, Biblioteca, Magazin Friedrichshagen.

POSADA CARBÓ, Eduardo. El Caribe colombiano: una historia regional (1870-1950). Bogotá: Banco de la República, 1998.

PROPAGANDA ACTIVIDADES NAZIS, 1937-1940. AGN, MRE, Diplomática y Consular, Caja 23 , carpeta 184 .

RECONOCIMIENTO de varios hijos naturales que hace Franz Copell. Barranquilla, 21 jun. 1926, Archivo Histórico del Atlántico, Fondo Notarías, Notaría Primera, Tomo 12, Escritura Pública Número 1147.

ROCA, Manuel. Empleados alemanes de la SCADTA bajo contrato. Bogotá, 23 jun. 1940, AGN, MRE, Diplomática y Consular, Caja 21, Carpeta 169.

SECCIÓN DE EXTRANJERÍA E IDENTIFICACIÓN DE LA POLICÍA NACIONAL. Informe de la Sección de extranjería e identificación de la policía nacional, en Barranquilla, al director general. Barranquilla, 23 de mayo de 1943. Archivo General de la Nación, MRE, Diplomática y Consular, Caja 23, Carpeta 181.

STEINWEIS, Alen. Art, ideology, and economics in nazi Germany: the reich chambers of music, theater, and the visual arts. London: The University of North Carolina Press, 1993.

TESTAMENTO abierto hecho por August Albert Johanes Lühr. Barranquilla, 21 agosto 1920, AHA, Fondo Notarías, Notaría Primera, Tomo 13, Escritura Pública Número 1822. 
Recebido em 18/04/2018

Aprovado em 24/04/2019

Universidade do Estado de Santa Catarina - UDESC Programa de Pós-Graduação em História - PPGH

Revista Tempo e Argumento Volume 11 - Número 28 - Ano 2019 tempoeargumento@gmail.com 